\title{
Povos indígenas e o ensino: reconhecendo o direito à inclusão das sociodiversidades no currículo escolar com a Lei n. 11.645/2008
}

Edson Silva*

\begin{abstract}
Resumo
Nas últimas décadas, diferentes grupos sociais conquistaram e ocuparam seus espaços, exigindo um repensar sobre a organização sociopolítica e a história do Brasil. Foram questionadas as concepçôes do país com uma cultura única e da mestiçagem como a identidade nacional. Identidades foram afirmadas, diferentes expressôes socioculturais passaram a ser reconhecidas e respeitadas. A partir de suas mobilizaçôes, os povos indígenas conquistaram também, nas últimas décadas, considerável visibilidade enquanto atores sociais, o que vem exigindo discussóes, formulaçóes e fiscalizaçóes de políticas públicas que respondam às demandas de direitos sociais específicos. A implantação da Lei n. 11.645/2008, que determinou a inclusão da história e culturas indígenas nos currículos escolares, possibilitará o respeito aos povos indígenas e o reconhecimento das sociodiversidades no Brasil.
\end{abstract}

Palavras-chave: povos indígenas, identidade, sociodiversidades, direitos, história.

Indigenous peoples and education: recognition of the right to inclusion of sociodiversities in the school curriculum as a result of Decree 11.645/2008

\begin{abstract}
In recent decades different social groups have conquered and occupied their spaces and demanded a rethinking of the socio-political organization and history of Brazil. The concept of a country identified by a single mestizo culture has been questioned. Identities have been affirmed and different socio-cultural expressions have been recognized and respected. In recent decades indigenous people, through their mobilizations, have also gained considerable visibility as social actors, all of which demands discussion, formulation, and inspection of public policies to meet the demands of specific social rights. The implementation of Decree $11.645 / 2008$, requiring that the history and culture of indigenous peoples be included in

* Doutor em História Social pela Universidade Estadual de Campinas (Unicamp). Professor no Centro de Educação/Colégio de Aplicação da Universidade Federal de Pernambuco (UFPE), Campus Recife. Leciona no Programa de Pós-Graduação em História, da UFPE, no PPGH, da Universidade Federal de Campina Grande (UFCG), e no curso de Licenciatura Intercultural na UFPE, Campus Caruaru, destinado à formação de professores/as indígenas em Pernambuco. E-mail: edson.edsilva@hotmail.com.
\end{abstract}


school curricula, will facilitate the bringing about of respect for indigenous peoples and the recognition of social diversity in Brazil.

Keywords: indigenous peoples, identity, social diversity, rights, history

\section{Afirmando as sociodiversidades indígenas}

O índio Gersem Baniwa (o povo Baniwa habita na fronteira entre o Brasil, Colômbia e Venezuela em aldeias nas margens do Rio Içana e seus afluentes, além de comunidades no Alto Rio Negro e nos centros urbanos de São Gabriel da Cachoeira, Santa Isabel e Barcelos/AM), é mestre e recém-doutor em Antropologia pela Universidade de Brasília (UnB). Publicou o livro $O$ indio brasileiro: o que você precisa saber sobre os povos indígenas no Brasil de hoje, tratando sobre a diversidade dos povos indígenas:

A sua diversidade, a história de cada um e o contexto em que vivem criam dificuldades para enquadrá-los em uma definição única. Eles mesmos, em geral, não aceitam as tentativas exteriores de retratá-los e defendem como um princípio fundamental o direito de se autodefinirem. (BANIWA, 2006, p. 47)

Após discorrer sobre as complexidades das organizaçóes sociopolíticas dos diferentes povos indígenas nas Américas, questionando as visóes etnocêntricas dos colonizadores europeus, o pesquisador indígena afirmou:

Desta constatação histórica importa destacar que, quando falamos de diversidade cultural indígena, estamos falando de diversidade de civilizaçóes autônomas e de culturas; de sistemas políticos, jurídicos, econômicos, enfim, de organizaçóes sociais, econômicas e politicas construídas ao longo de milhares de anos, do mesmo modo que outras civilizaçóes dos demais continentes europeu, asiático, africano e a Oceania. Não se trata, portanto, de civilizaçóes ou culturas superiores ou inferiores, mas de civilizaçóes e culturas equivalentes, mas diferentes. (BANIWA, 2006, p. 49)

Ao tratar da chamada identidade cultural brasileira, conclui:

Desse modo, podemos concluir que náo existe uma identidade cultural única brasileira, mas diversas identidades que, embora não formem um conjunto monolítico e exclusivo, coexistem e convivem de forma harmoniosa, facultando e enriquecendo as várias maneiras possíveis de indianidade, 
brasilidade e humanidade. Ora, identidade implica a alteridade, assim como a alteridade pressupóe diversidade de identidades, pois é na interação com o outro não-idêntico que a identidade se constitui. $\mathrm{O}$ reconhecimento das diferenças individuais e coletivas é condição de cidadania quando identidades diversas são reconhecidas como direitos civis e políticos, consequentemente absorvidos pelos sistemas políticos e jurídicos no âmbito do Estado Nacional. (BANIWA, 2006, p. 49)

Portanto, faz-se extremamente necessário ter presente que tratar dos grupos que se convencionou chamar genericamente de "índios" é se confrontar com uma situação parecida ao olhar um caleidoscópio: são povos em suas múltiplas expressóes socioculturais, diferentes entre si e de nossa sociedade. Assim, ainda que seja possível encontrar algumas semelhanças entre os diferentes povos indígenas que habitam nas diversas regióes do Brasil, cada povo indígena é singular em suas expressóes socioculturais e organizaçóes sociopolíticas, inseridas em processos e situações históricas peculiares. Pensar os povos indígenas é, então, pensar sempre em experiências plurais e diferenciadas.

\section{Reconhecendo as sociodiversidades, repensando o Brasil}

Por quais razões atualmente são obrigatórias rampas em prédios públicos, destinadas aos portadores de necessidades especiais? Por que existem delegacias exclusivas para as mulheres? Por que o Estatuto do Idoso? E o Estatuto da Criança e do Adolescente (ECA)? Por que a Lei n. 11.645/2008, que tornou obrigatória a inclusão nos currículos escolares do ensino de História e Culturas Afro-brasileiras e Indígenas? Quais as razóes do reconhecimento legal de direitos específicos e diferenciados na atualidade?

Em um trecho da Carta às esquerdas, recentemente publicada por Boaventura de Souza Santos, lemos: "O mundo diversificou-se e a diversidade instalou-se no interior de cada país. A compreensão do mundo é muito mais ampla que a compreensão ocidental do mundo; não há internacionalismo sem interculturalismo" (SANTOS, 2011). O renomado sociólogo português, conhecido por seu apoio explícito às mobilizaçóes políticas dos diferentes grupos sociais em países abaixo da linha do Equador (América do Sul, África e Ásia), enfatizou que reconhecer as sociodiversidades exige o 
reconhecimento dos direitos às diferenças que constituem o mundo atual, significando a negação da visão de uma suposta cultura ocidental como única, a superação do eurocentrismo e do etnocentrismo.

As respostas às perguntas formuladas acima podem ser encontradas observando a organização sociopolítica no Brasil contemporâneo. Nas últimas décadas, em novos cenários políticos, os movimentos sociais com diferentes atores conquistaram e ocuparam seus espaços, reivindicando o reconhecimento e o respeito às sociodiversidades. Identidades foram afirmadas, diferentes expressóes socioculturais passaram a ser reconhecidas e respeitadas, o que exigiu discussóes, formulaçóes e fiscalizaçóes de políticas públicas que respondam às demandas de direitos sociais específicos.

Todavia, faz-se necessário ter presente que o reconhecimento dessa nova configuração das sociodiversidades no Brasil não ocorre sem muitas tensóes e conflitos, a exemplo dos acalorados debates sobre as cotas para negros nas universidades. Porém, durante muito tempo, no Brasil vigorou, e sem restriçóes, a chamada Lei do Boi. Tratava-se da Lei n. 5.465, de 03 de julho de 1968, que ficou assim conhecida por beneficiar filhos de fazendeiros e criadores de gado que ingressavam sem vestibular nas universidades públicas nos cursos de Agronomia e Veterinária. Na verdade, a Lei passou a valer para todos os cursos. E só foi revogada em dezembro de 1985. Ou seja, durante muitos anos em nosso país existiram, e sem discussóes, cotas para ricos nas universidades públicas, pois a lei não beneficiava filhos de trabalhadores pobres no campo.

Os debates sobre o reconhecimento e respeito às sociodiversidades no Brasil contemporâneo exigem, portanto, um repensar sobre a história do país, discussóes sobre a chamada formação da sociedade brasileira e da identidade nacional. A respeito da existência de uma suposta cultura brasileira, nordestina, sertaneja, pernambucana, etc. Esses debates também problematizam as ideias e concepçóes a respeito da mestiçagem, sobre os lugares dos índios, negros e outras minorias que formam a grande maioria da população em nosso país. A partir dessas discussóes questionam-se os posicionamentos de intelectuais, pesquisadores e conhecidas personalidades do mundo artístico, vinculadas às esquerdas, a exemplo do antropólogo Darcy Ribeiro, os compositores e cantores Chico Buarque, Tom Zé, Lenine e tantos outros que defendem uma suposta cultura e identidade brasileira. 


\section{Produzindo uma identidade nacional eliminando as diferenças:} a mestiçagem

A concepção e afirmação de uma identidade, de uma cultura nacional no Brasil, remontam ao século XIX. Em meados daquele século, quando ainda não tínhamos universidades públicas no Brasil, o Instituto Histórico Geográfico Brasileiro (IHGB), sediado no Rio de Janeiro, a capital do Império, reunia os "homens de ciência", que formavam a elite pensante do país. O IHGB promoveu em 1843 o concurso "Como se deve escrever a História do Brasil”, e o vencedor foi o alemão Karl von Martius, que, com o seu compatriota Johann von Spix, viajaram em uma expedição científica por todo Brasil entre 1817 a 1820 . Na sua proposta sobre a escrita da história do Brasil, o naturalista Von Martius salientou a importância do índio, do negro e do branco português na formação histórica do país. Todavia, ressaltava a maior relevância do colonizador, pela sua responsabilidade civilizatória. A ênfase nas relaçóes das três raças configurava-se na defesa da mestiçagem, ideia que foi posteriormente retomada por vários pensadores sobre o Brasil.

No pensamento literário, com o Romantismo, o índio foi eleito símbolo da identidade nacional, o que foi expresso, por exemplo, nas conhecidas obras indianistas de José de Alencar: O guarani (1857), Iracema (1865) e Ubirajara (1874). Já $O$ sertanejo (1875) situa-se no conjunto da literatura regionalista de Alencar, em que o autor escreveu um romance temático para cada região do Brasil. Em O sertanejo, o personagem principal do enredo é Arnaldo, apresentado como homem arredio, bom, simples e servidor, primeiro vaqueiro de uma fazenda no interior do Ceará. Figura excepcional e misteriosa, com o pleno conhecimento e domínio da natureza, tendo o hábito de dormir no alto de árvores na mata, cercado de animais selvagens, sabendo distingui-los como ninguém.

Pelas características de Arnaldo descritas por Alencar, pode-se atribuí-las às de um indígena que, carregando as peculiaridades de sua condição, convivia integrado ao mundo social da fazenda onde trabalhava. Arnaldo foi apresentado como submisso ao seu senhor e patrão. A sua submissão era o preço do seu reconhecimento. Para Alencar, a passividade foi o preço da integração de Arnaldo no mundo dos colonizadores, que negavam a sua identidade indígena. Tanto essas imagens acerca dos indígenas, como as expressadas nas pinturas dos naturalistas viajantes no século XIX foram incorporadas ao imaginário coletivo do país na época, e, posteriormente, reproduzidas nos manuais didáticos (SILVA, 1995, p. 26-27). 
Com o Realismo/Naturalismo nas últimas décadas do século XIX, a ideia da mestiçagem como explicação do Brasil foi retomada. O livro O mulato (1881), de Aluízio Azevedo, por seu título, expressa a concepção da mestiçagem. $\mathrm{Na}$ ascensão da literatura realista e naturalista influenciada pelos pressupostos raciais deterministas, em oposição ao Romantismo e ao Indianismo, houve a exaltação das imagens do mestiço e, portanto, as imagens negras e indígenas foram deixadas de lado nos escritos literários. Sílvio Romero, em sua História da Literatura Brasilei$r a$, que começou a ser publicada no início da última década do século XIX, afirmou: "O mestiço é o produto fisiológico, étnico e histórico do Brasil; é a forma nova de nossa diferenciação nacional" (ROMERO, 1980, p. 120).

Para Sílvio Romero, a história do Brasil era uma história da mestiçagem. A mestiçagem que seria superada pelo embranquecimento do português preponderante:

Não quero dizer que constituiremos uma nação de mulatos; pois que a forma branca vai prevalecendo e prevalecerá; quero dizer apenas que o europeu aliou-se aqui a outras raças, e desta uniáo saiu o genuíno brasileiro, aquele que não se confunde mais com o português e sobre o qual repousa o nosso futuro. (ROMERO, 1943, p. 104)

A mestiçagem, portanto, seria uma condição transitória.

O mestiço é a condição desta vitória do branco, fortificando lhe o sangue para habita-lo aos rigores do clima. É uma forma de transição necessária e útil que caminha para aproximar-se do tipo superior. Pela seleção natural, todavia, depois de apoderado do auxilio de que necessita, o tipo branco irá tomando a preponderância, até mostrar-se puro e belo como no velho mundo. (ROMERO, 1943, p. 231)

A ideia da mestiçagem com explicação do Brasil que se consolidava no final do século XIX foi retomada no século seguinte. Ao participar, representando o Brasil, do Congresso Universal das Raças, realizado na cidade de Londres em 1911, o cientista João Baptista de Lacerda, pesquisador do Museu Nacional no Rio de Janeiro, exaltou a mestiçagem brasileira e defendeu a imigração para o embranquecimento do país e a extinção da raça negra (SCHWARCZ, 2011), assim como fizera Sílvio Romero. 
A mestiçagem foi defendida também com o Modernismo, a partir da Semana de Arte Moderna, de 1922. Na obra mais conhecida desse movimento literário e político - o livro Macunaima, de Mário de Andrade, publicado em 1928 -, o herói Macunaíma foi apresentado como a síntese da mestiçagem, louvado como símbolo da identidade cultural brasileira nas disputas com a invasão cultural estrangeira.

$\mathrm{Na}$ década de 1930 aconteceram várias significativas mudanças socioculturais no Brasil, como a ascensão de Getúlio Vargas ao poder, a industrialização crescente no Sudeste, com o consequente enriquecimento e aparecimento da classe média urbana, o início das migraçóes do campo para as cidades, principalmente do "Sul maravilha" (São Paulo), o que provocou também mudanças na configuração sociocultural do país. Alguns autores afirmam ter ocorrido, nesse período, um redescobrimento, uma refundação do Brasil. Nesse contexto sociopolítico, a história do país foi discutida e as concepções, revistas na afirmaçáo de uma identidade sociocultural para o país.

É desse período a publicação dos conhecidos livros Casa grande \& senzala (1933), de Gilberto Freyre, Raizes do Brasil (1936), de Sérgio Buarque de Holanda, e Formação do Brasil contemporâneo (1942), de Caio Prado Jr. Esses autores, ao discutirem "as raízes" e "a formação" do Brasil em sintonia com aquele momento sociopolítico, buscavam, além de explicar o passado, apontar um projeto de futuro para o país. Propunham-se explicaçóes em que uma identidade nacional, a identidade brasileira, notadamente em Casa grande \& senzala, era resultado de uma conformidade mestiça.

O nacionalismo e o desenvolvimentismo foi a tônica dos anos seguintes, inclusive expressos no período da ditadura militar. Com seus arroubos nacionalistas, aos defensores da ditadura militar que se instalou no Brasil em 1964 interessou também sobremaneira a exaltação de um país com a identidade única, caminhando a passos largos para o desenvolvimento. Progresso e unidade cultural do gigante país verde e amarelo, como afirmavam os militares, eram temas indissociáveis nos discursos dos defensores da chamada nação brasileira. $\mathrm{O}$ discurso da monocultura nacional foi também defendido pelas esquerdas em seus projetos políticos de oposição à ditadura militar. O antropólogo, escritor e educador Darcy Ribeiro, que se dizia um político apaixonado pelo Brasil, foi um exemplo disso. Ele foi um dos últimos autores que buscou formular uma explicação, uma síntese, uma teoria geral para a história do Brasil, por meio de seus vários livros, entrevistas e romances, publicados durante e depois do fim da ditadura. 
A ideia de um Brasil moderno formado por uma macroetnia foi retomada e advogada pelo antropólogo no livro $O$ povo brasileiro. Segundo o autor, era a síntese de sua "teoria de Brasil". Nesse livro, Darcy Ribeiro (1995), mais uma vez, enfatizou a sua defesa do mulato como símbolo do Brasil e síntese da fusão das diferentes expressóes socioculturais no país. Os méritos de Darcy Ribeiro decorrem de ter sido ele o primeiro autor que discutiu o "problema indígena" de uma forma ampla, e por sua explícita posição política em denunciar as opressôes sobre os índios na história do Brasil, o que tornou as ideias do antropólogo bastante conhecidas. A obra Os indios e a civilização (RIBEIRO, 1982), com várias ediçóes, devido a sua quantidade de informaçóes e sistematização de dados, "continua a ser uma peça insubstituível, referência obrigatória para qualquer apreciação global da população indígena brasileira” (OLIVEIRA, 2001, p. 421). Além de ter sido traduzido para outras línguas, adotado nos cursos de Ciências Sociais no Brasil, formando uma geração de estudantes, esse livro foi também lido por profissionais de outras áreas e pelo público em geral. As ideias de Darcy Ribeiro contidas nesse e em outros livros do autor, que discutem o Brasil, muito influenciaram a visão de outros estudiosos e o senso comum sobre os índios e as expressóes socioculturais do país.

\section{Reafirmando as diferenças, questionando a mestiçagem}

O historiador negro jamaicano Stuart Hall, que se tornou um renomado professor, lecionando em universidades na Inglaterra, a partir da perspectiva gramsciana, discutiu o conceito de hegemonia nas relações socioculturais. Ao tratar sobre a ideia da nação moderna, esse autor debateu acerca das construçôes dos símbolos, discursos e representações a respeito de supostas culturas e identidades nacionais hegemônicas que buscam apagar as diferentes expressóes socioculturais.

Para Hall (1999, p. 50-51),

[a]s culturas nacionais são compostas náo apenas de instituições culturais, mas também de símbolos e representaçôes. Uma cultura nacional é um discurso - um modo de construir sentidos que influencia e organiza tanto nossas açóes quanto a concepção que temos de nós mesmos. As culturas nacionais, ao produzir sentidos sobre "a nação", sentidos com os quais podemos nos identificar, constroem identidades. Esses sentidos estão contidos 
nas estórias que são contadas sobre a nação, memórias que conectam seu presente com o seu passado e imagens que dela são construídas.

A afirmação da mestiçagem como identidade do Brasil pode ser compreendida e discutida a partir da perspectiva apontada por Stuart Hall.

A música "Leão do Norte" é uma composição de Paulo César Pinheiro e Lenine, sendo cantada por este último, que é pernambucano. A letra dessa música é um exemplo, seja para o local/regional, seja para o nacional, das construçóes das imagens representativas de uma visão de identidade cultural geral. Cabe lembrar que o próprio título da música remete aos discursos usados pela elite pernambucana do século XIX, para afirmar a soberania da província nas disputas políticas com as oligarquias do Sudeste do país. Portanto, o título e a letra da música expressam ufanismo, patriotismo e afirmações identitárias.

Observemos que na letra da referida música seus autores, além de se identificarem, dizem de onde falam: "Eu sou mameluco, sou de Casa Forte Sou de Pernambuco, sou o Leão do Norte". Ou seja, afora serem mestiços, moram em Casa Forte, tradicional bairro recifense habitado pela "açucarocracia” pernambucana, as famílias e seus descendentes de senhores de engenho do passado e ricos usineiros do presente. O bairro é conhecido por ser uma espécie de ilha de conforto, suntuosidade e tranquilidade no Recife, no que diz respeito às condiçóes de moradia, centro comercial e serviços públicos. Por que os músicos náo afirmaram serem mestiços moradores em uma das várias comunidades pobres existentes na periferia da capital pernambucana?!

Mesmo tendo presente que os artistas têm a plena liberdade de expressóes e que, em se tratando da música vista com uma obra de arte, a metáfora é uma linguagem intrínseca no universo das artes, a letra da música em questão nos possibilita reflexóes sobre os sentidos do seu conteúdo a partir da temática que estamos tratando, a construção de uma identidade cultural. Em uma breve análise da letra dessa música, percebemos que os autores evocam as muitas e diversas expressōes socioculturais existentes em todo o estado de Pernambuco. Citam personalidades renomadas do âmbito da Cultura, sejam literatos, como Ariano Suassuna, músicos, como Luiz Gonzaga, ou animadores de expressóes socioculturais populares, como o Velho Faceta, que ficou bastante conhecido por liderar as apresentaçóes do Pastoril em bairros do Recife. Da mesma forma indistinta, são citadas 
expressôes socioculturais de diferentes localidades, espaços e temporalidades que ocorrem em Pernambuco. Todas colocadas lado a lado, em um mesmo plano supostamente valorativo.

Transparece, ainda, na leitura da letra da referida música a evocação de uma tradição comum, de uma identidade pernambucana, fundada em uma memória coletiva, mas atemporal, em que pessoas, lugares, expressóes, objetos, lembranças e eventos compóem a cultura da pernambucanidade, a nação pernambucana, representada no que vem a ser o Leão do Norte.

À semelhança da música "Leão do Norte", se realizarmos uma pesquisa, iremos encontrar outras cançóes, poesias e conhecidos textos que, nas diferentes regióes do Brasil, evocam imagens laudatórias de uma cultura local, como expressivas de uma suposta identidade geral regional, sejam elas denominadas amazônica, pantaneira, gaúcha, paulista carioca, mineira, baiana e tantas outras.

O historiador Stuart Hall afirmou que um dos elementos principais que expressam a cultura de uma nação seria a narrativa, ao fornecer imagens, panoramas, cenários, eventos históricos, símbolos e rituais que representam a partilha de experiências e dá sentido à nação como uma comunidade imaginada. Um conjunto de símbolos que torna o lugar agradável aos seus habitantes, o solo nativo que confere uma identidade a ser reafirmada publicamente. Ocorreria, ainda, uma ênfase nas origens, na continuidade, na tradição e na intemporalidade (HALL, 1999, p. 52-53). Tais reflexôes são pertinentes ao analisarmos a letra da música em discussão.

Portanto, é preciso descontruir uma suposta identidade nacional, ou outras afirmaçóes tais como a regional, expressa em uma cultura hegemônica que nega, ignora e despreza as diferenças socioculturais. Também, é necessário questionar uma suposta identidade e cultura nacional que se constituem pelo discurso impositivo de um único povo, uma unidade anunciada muitas vezes em torno de ideia de raça, um tipo biológico. Pensemos no caso do Brasil, as ideias sobre o mulato, o mestiço, o gaúcho, o paulista, o mineiro, o nordestino, o sertanejo, o pernambucano, dentre outras.

As concepçóes de uma identidade e cultura nacional escondem as diferenças sejam de classes sociais, de gênero e etnia, ao buscar uniformizá-las. Recusam também os processos históricos marcados pelas violências de grupos politicamente hegemônicos. Negam, ainda, as violências sobre grupos subalternos, a exemplo de povos indígenas e oriundos da África, que foram submetidos a viverem em ambientes coloniais. Observemos, também, que 
as identidades nacionais, além de serem fortemente marcadas pelo etnocentrismo, são também pelo sexismo: se diz o mulato, o mestiço, o pernambucano, acentuando-se o gênero masculino.

Faz-se necessário, então, problematizar as ideias e afirmações de identidades generalizantes, como a mestiçagem no Brasil, um discurso utilizado para negar, desprezar e suprimir as sociodiversidades no país. Afirmar os direitos às diferenças é, pois, questionar o discurso da mestiçagem como identidade nacional, usado para esconder a história de índios e negros na história do Brasil.

\section{Reconhecendo os direitos às diferenças, às sociodiversidades}

Na versão em vídeo-documentário do citado livro $O$ povo brasileiro, publicado pelo antropólogo Darcy Ribeiro, são apresentadas belíssimas imagens para exemplificar a colcha de retalhos de culturas que, unificadas, formam o Brasil, em uma só identidade nacional resultante da mistura de todas elas, diferentemente do que afirmou o índio Gersem Baniwa. Cremos que, assim como ocorreu com as imagens, os narradores nesse documentário não foram escolhidos ao acaso. Conhecendo a obra de Darcy, as indicaçóes são de que tudo foi pensado e escolhido de forma detalhada, para facilitar a interação do público com as ideias, o conteúdo expressado no pensamento do autor.

Nesse documentário, dentre outros narradores, aparecem cantores e compositores, a exemplo de Chico Buarque e Tom Zé. Acreditamos que se esses cantores comprometem suas imagens e discursos, é porque também comungam com as ideias de Darcy Ribeiro. Isso porque esses conhecidos artistas, por mais de uma vez, expressaram em suas obras as concepçóes de uma identidade, uma cultura nacional, como aparece na citada música "Leão do Norte", cantada por Lenine. São autores de uma geração cujas vozes e concepçóes acreditam em uma brasilidade mestiça. As atuais discussóes sobre as sociodiversidades existentes no Brasil, por sua vez, questionam as ideias dessa geração, ainda que sejam pessoas historicamente vinculadas a um pensamento da esquerda política e atuem na defesa da democracia.

Ao tratar do contexto em que emergiu a Lei n. 10.639/2003, que determinou a inclusão nos currículos escolares das escolas no Brasil do ensino da História da África e da cultura afro-brasileira, a reconhecida pesquisadora Nilma Lino Gomes (UFMG) afirmou: 
Muitas vezes, o caráter universal e abstrato do discurso em prol de uma democracia para todos acaba uniformizando e homogeneizando trajetórias, culturas, valores e povos. Por isso, os movimentos sociais cada vez mais buscam ampliar a noção de democracia, a fim de que ela insira a diversidade e apresente alternativas para lidar com as políticas de identidade. Essa outra perspectiva de democracia deverá radicalizar ainda mais a luta pelos direitos sociais, incluindo nessa o direito à diferença. Assim, a democracia estará mais próxima das vivências concretas dos diferentes sujeitos sociais e de sua luta pela construção da igualdade social que incorpore e politize a diversidade. (GOMES, 2008, p. 70; grifos da autora)

A pesquisadora enfatizou as mobilizaçóes sociais que resultaram na inserção da diversidade nos currículos escolares, mas alertou também para a necessidade de outras iniciativas políticas e pedagógicas reivindicadas pelos movimentos sociais, a exemplo da organização das escolas e formação de professores/as indígenas, da educação inclusiva, das escolas e formação de professores/as do campo, da educação ambiental. Enfim, ao lado de outras temáticas igualmente necessárias, devem ser tratadas as sociodiversidades indígenas.

Afirmar as sociodiversidades indígenas no Brasil é, portanto, buscar compreender as possibilidades de coexistências socioculturais, fundamentadas nos princípios da interculturalidade.

A interculturalidade é uma prática de vida que pressupóe a possibilidade de convivência e coexistência entre culturas e identidades. Sua base é o diálogo entre diferentes, que se faz presente por meio de diversas linguagens e expressôes culturais, visando à superação de intolerância e da violência entre indivíduos e grupos sociais culturalmente distintos. (BANIWA, 2006, p. 51)

Somente a partir da nova conjuntura política com o fim da ditadura, as ideias polarizadas, bem como as totalizantes, que perpassavam as discussóes sobre a identidade do país, foram explicitamente colocadas em discussão. Timidamente, foram dados os primeiros passos que rediscutiam a mestiçagem como a expressão de uma suposta identidade brasileira. Os debates públicos e acadêmicos em torno das questôes de gênero, da temática negra, dentre outras, ganharam corpo nos anos seguintes, colocando em xeque a suposta identidade nacional advogada anteriormente. 


\section{A Lei n. 11.645/2008: limites e possibilidades para o (re)conhecimento das sociodiversidades indígenas}

Onde estão os índios?! As dúvidas ou as respostas negativas a essa pergunta ainda são ouvidas pela imensa maioria da população, e até mesmo por pessoas mais esclarecidas. O pouco conhecimento generalizado sobre os povos indígenas está associado basicamente à imagem do "índio", que é tradicionalmente veiculada pela mídia: um "índio" genérico, com um biótipo formado por características correspondentes aos indivíduos de povos habitantes na regiáo amazônica e no Xingu, com cabelos lisos, pinturas corporais e abundantes adereços de penas, nus, moradores das florestas, de culturas exóticas, etc.

Ou também as populações indígenas são chamadas de "tribos", a partir da perspectiva etnocêntrica e evolucionista de uma suposta hierarquia de raças, em que os índios ocupariam obviamente o último degrau. $\mathrm{Ou}$, ainda, imortalizados pela literatura romântica produzida no século XIX, como nos livros de José de Alencar, em que são apresentados índios belos e ingênuos, ou valentes guerreiros e ameaçadores canibais, ou seja, bárbaros, bons selvagens ou heróis.

Mas essas visôes sobre os índios vêm mudando nos últimos anos. $\mathrm{E}$ essa mudança ocorre em razão da visibilidade política conquistada pelos próprios índios. As mobilizaçôes dos povos indígenas em torno das discussóes e debates para a elaboração da Constituição em vigor aprovada em 1988 e as conquistas dos direitos indígenas fixados na Lei maior do país possibilitaram a garantia dos direitos (demarcação das terras, saúde e educação diferenciadas e específicas, etc.), além da ênfase de que a sociedade em geral (re)descubra os índios.

Além disso, a nossa sociedade, ainda como resultado da organização e mobilizaçóes dos movimentos sociais, se descobre plural, repensa seu desenho: o Brasil não tem uma identidade nacional única. Somos um país de muitos rostos, expressóes socioculturais, étnicas, religiosas, etc. As minorias (maiorias), sejam mulheres, ciganos, pessoas negras, idosas, crianças, portadoras de necessidades especiais, reivindicam o reconhecimento e o respeito de seus direitos. Um exemplo muito simples disso: é obrigatório em todos os prédios públicos rampas de acesso para pessoas deficientes. E antes não existia essa necessidade? Sim, existia. Mas hoje a sociedade reconhece esse direito. 
Os índios, então, conquistam o (re)conhecimento do respeito a seus direitos específicos e diferenciados, a partir dessa ótica: um país é a sociedade que se repensa, se vê em sua multiplicidade, pluralidade e sociodiversidade, expressada também pelos povos indígenas em diferentes contextos sócio-históricos, embora esse reconhecimento exija também posturas e medidas das autoridades governamentais para ouvir dos diferentes sujeitos sociais a necessidade de novas políticas públicas, que reconheçam, respeitem e garantam essas diferenças.

Um exemplo disso é, na educação, a formulação de políticas educacionais inclusivas das histórias e expressóes culturais no currículo escolar, nas práticas pedagógicas. Essa exigência deve ser atendida com a contribuição de especialistas, a participação e envolvimentos plenos dos próprios sujeitos sociais na formação de futuros/as docentes, na formação continuada daqueles/as que atuam e fundamentalmente na produção de subsídios didáticos, seja nas universidades, nas secretarias estaduais e municipais, para o ensino em todos os níveis escolares. Só a partir disso é que deixaremos de tratar as diferenças socioculturais como estranhas, exóticas e folclóricas, de modo a (re)conhecer em definitivo "os índios" como povos indígenas, em seus direitos de expressóes próprias que podem contribuir decisivamente para a nossa sociedade, para todos nós.

Sem dúvida, é no âmbito da escola/educação formal, em seus vários níveis hierárquicos, que se pode constatar a ignorância que resulta nas distorçôes a respeito dos índios. A Lei n. 11.645, de março de 2008, tornou obrigatório o ensino sobre a história e culturas indígenas nos currículos escolares no Brasil. E ainda que careça de maiores definiçôes, objetivou a superação dessa lacuna na formaçáo escolar, contribuindo para o reconhecimento e a inclusão das diferenças étnicas dos povos indígenas, para se repensar em um novo desenho do Brasil em sua diversidade e da pluralidade culturais.

Para a implementação da Lei n. 11.645/08, é preciso ter claros os diferentes níveis de responsabilidades, bem como os desafios para sua real efetivação. No âmbito federal, o Ministério da Educação (MEC) tem uma tarefa extremamente importante: apoiar a produção de subsídios didáticos destinados aos/às educadores/as nas escolas públicas estaduais e municipais, de acordo com as realidades distintas no país.

Ao Ministério Público Federal e nos Estados cabe fiscalizar a execução da implementação da lei nas redes públicas e privadas de ensino, inclusive nas faculdades, universidades e instituiçóes congêneres que atuam na formação de professores/as. 
No nível das universidades públicas e privadas, faz-se necessária a inclusão de cadeiras. Sobre a temática indígena, no âmbito das Ciências Humanas e Sociais, bem como nos demais campos do conhecimento acadêmico, deve-se incluir a discussão dos saberes indígenas. Por exemplo, na área da Matemática, podem ser discutidos os saberes matemáticos de povos culturalmente distintos do pensamento hegemônico ocidental.

Caberá às secretarias estaduais e municipais de educação disponibilizar, favorecer o acesso aos subsídios produzidos pelo MEC e, também, produzir materiais didáticos de modo a enfocar as realidades locais dos povos indígenas. É de fundamental importância, ainda, capacitar os quadros técnicos dessas instâncias governamentais, no âmbito do combate aos racismos institucionais. Ainda nas esferas governamentais locais, são necessários, com a participação dos indígenas, especialistas reconhecidos/as, promoção de seminários, encontros de estudos, etc., sobre a temática indígena para professores/as e demais trabalhadores/as na educação.

Pensando em algumas propostas e sugestôes, o MEC, em suas instâncias competentes, deve acompanhar a implementação da Lei n. 11.645/08 no âmbito dos currículos dos cursos de licenciatura e formação de professores/as. Isso significará a inclusão de cadeiras obrigatórias que tratem especificamente da temática indígena, principalmente em cursos das áreas das Ciências Humanas e Sociais. Cabe às universidades estimular, apoiar e, ainda, viabilizar os meios necessários para a participação efetiva do professorado, alunos/as e técnicos em eventos acadêmicos que tratem da temática indígena.

Por meio de convênios com o MEC e as secretarias estaduais e municipais, que as universidades produzam materiais didáticos que tratem da temática indígena para serem disponibilizados para o ensino público. As secretarias estaduais e municipais incluam, ainda, a temática indígena nos estudos, capacitaçóes periódicas e formação continuada. Temática esta que deve ser abordada na perspectiva das sociodiversidades historicamente existentes no Brasil: por meio de cursos, seminários, encontros de estudos específicos e interdisciplinares destinados ao professorado e demais trabalhadores/as em educação, com a participaçáo de indígenas e assessoria de especialistas reconhecidos, bem como com a aquisição de livros que tratem da temática indígena, destinados ao acervo das bibliotecas escolares.

Que essas secretarias favoreçam as pesquisas, bem como estimulem os/as interessados/as em cursos de aprofundamento, como pós-graduação. 
Quanto às citadas secretarias, que promovam estudos específicos para que o professorado possa conhecer os povos indígenas no Brasil, possibilitando uma melhor abordagem ao tratar da temática indígena em sala de aula, particularmente nos municípios onde atualmente habitam esses povos.

Intensificar a produção, com assessoria de pesquisadores/as especialistas, de vídeos, cartilhas, subsídios didáticos, etc., sobre os povos indígenas, para serem utilizados em sala de aula. Proporcionar o acesso a publicaçóes, livros, periódicos, etc., como fonte de informação e pesquisa sobre os povos indígenas.

É salutar a promoção de momentos de intercâmbios entre os povos indígenas, educadores e estudantes durante o calendário letivo, por meio de visitas previamente preparadas às aldeias, bem como de indígenas às escolas. É importante que essa ação seja desenvolvida principalmente nos municípios onde atualmente habitam povos indígenas, como forma de buscar a superaçáo dos preconceitos e as discriminaçóes.

É preciso discutir e propor o apoio aos povos indígenas, por meio do estímulo ao alunado com a realização de abaixo-assinados, cartas às autoridades com denúncias e exigências de providências para as violências contra os povos indígenas, assassinatos de suas lideranças, etc. Assim, estimula-se, por meio de manifestaçóes coletivas na sala de aula, o apoio às campanhas de demarcação das terras e garantia dos direitos dos povos indígenas.

Enfim, promover, seja nas universidades, nas escolas ou nos demais espaços institucionais, açóes pautadas na perspectiva da compreensão das sociodiversidades e do reconhecimento dos direitos dos povos indígenas, bem como do reconhecimento de que o Brasil é um país pluricultural e pluriétnico.

No novo cenário político, com outros atores, os povos indígenas conquistaram e ocuparam seus espaços, reivindicando o reconhecimento e o respeito de suas expressóes étnicas e socioculturais, bem como das condiçôes para vivenciá-las. A mestiçagem enquanto apagamento, sombra que escondia as diferenças, perdeu a primazia do status explicativo sobre o país. O reconhecimento das sociodiversidades, além de provocar um repensar do país, vem exigindo políticas públicas que deem conta dessa realidade. Daí a necessidade de se debruçar sobre a história do Brasil para melhor compreender, no presente, as diversidades socioculturais em um país com dimensóes continentais, com suas peculiaridades regionais e locais. 
A Lei n. 11.645/2008, ao determinar a inclusão da história e culturas dos povos indígenas no currículo escolar, questiona as ideias e visôes sobre a sociedade e a história do Brasil como uma única expressão sociocultural. A efetivação da lei possibilita discutir e problematizar o lugar dos índios, melhor dizendo, dos povos indígenas em nossa sociedade, na história do Brasil, além de reconhecer os legítimos direitos às diferentes sociodiversidades expressadas pelos povos indígenas.

Em nossa sociedade, a escola tem um papel privilegiado de formação humana que deve responder às demandas sociais. Nesse sentido é que a implementação da Lei n. 11.645/2008 possibilitará o reconhecimento das diferenças socioculturais existentes no Brasil, o reconhecimento dos direitos das sociodiversidades dos povos indígenas. Ainda que se tenha presentes as dificuldades e desafios dos processos de ensino-aprendizagem, do fazer pedagógico, a escola é um lócus em que, com a efetivação da lei, será possível, no ambiente escolar, viabilizar "espaços que favoreçam o reconhecimento da diversidade e uma convivência respeitosa baseada no diálogo entre os diferentes atores sociopolíticos, oportunizando igualmente o acesso e a socialização dos múltiplos saberes" (SILVA, 2010, p. 46). Dessa forma, contribui-se na formação de cidadãos/as críticos/as.

\section{Referências}

BANIWA, G. dos S. L. O indio brasileiro: o que você precisa saber sobre os povos indígenas no Brasil de hoje. Brasília: MEC/Secad/Museu Nacional/ UFRJ, 2006.

GOMES, N. L. A questão racial na escola: desafios colocados pela implementação da Lei 10.639/2003. In, MOREIRA, Antonio F; CANDAU, Vera M. Multiculturalismo: diferenças culturais e práticas pedagógicas. 2. ed. Petrópolis, RJ: Vozes, 2008. p. 67-89.

HALL, S. A identidade cultural na pós-modernidade. 3. ed. Rio de Janeiro: DP\&A, 1999.

OLIVEIRA, J. P. de. Darcy Ribeiro: os índios e a civilização. In, MOTA, D. Leonardo. (Org.). Introdução ao Brasil: um banquete no trópico. São Paulo: SENAC, 2001. v. 2, p. 405-422. 
RIBEIRO, D. O povo brasileiro: a formação e o sentido do Brasil. 2. ed. São Paulo: Cia. das Letras, 1995.

. Os indios e a civilizaçâo: a integração das populações indígenas no Brasil moderno. 4. ed. Petrópolis, RJ: Vozes, 1982.

ROMERO, S. História da Literatura Brasileira. 7. ed. Rio de Janeiro: José Olympio, 1980. . História da Literatura Brasileira. v. 1. Rio de Janeiro: José Olympio, 1943.

SANTOS, B. de S. Carta às esquerdas. Radis, n. 110, out. 2011, p. 23.

SCHWARCZ. L. M. Previsóes são sempre traiçoeiras: João Baptista de Lacerda e seu Brasil branco. História, Ciências, Saúde - Manguinhos, Rio de Janeiro, v. 18, n. 1, jan.-mar. 2011, p. 225-242.

SILVA, M. da P. da. A temática indígena no currículo escolar à luz da Lei 11.645/2008. Cadernos de pesquisa, Sáo Luís, UFMA, v. 17, n. 2, maio/ago. 2010, p. 39-47.

SILVA, E. O lugar do indio. Conflitos, esbulhos de terras e resistência indigena no Século XIX: o caso de Escada-PE (1860-1880). 1995. Dissertação (Mestrado em História) - Programa de Pós-Graduação em História, Universidade Federal de Pernambuco, Recife, PE, 1995.

Recebido em: 18 nov. 2011.

Aceito em: 15 maio 2012. 